Fetal Diagnosis and Therapy
Fetal Diagn Ther 2015;37:81-92

DOI: $10.1159 / 000368605$
Received: August 5, 2014

Accepted after revision: September 21, 2014

Published online: February 3, 2015

\title{
Update on the Pathophysiological Implications and Clinical Role of Angiogenic Factors in Pregnancy
}

\author{
Elisa Llurba ${ }^{a, b}$ Fatima Crispic $^{c}$ Stefan Verlohren ${ }^{d}$ \\ ${ }^{a}$ Department of Obstetrics, Maternal-Foetal Medicine Unit, Vall d'Hebron University Hospital, Universitat Autònoma

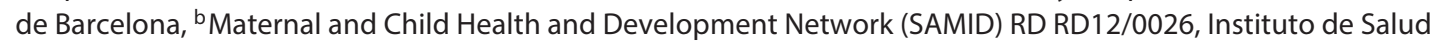 \\ Carlos III, and ' Fetal i+D Fetal Medicine Research Center, IDIBAPS, BCNatal|Barcelona Center for Maternal Fetal \\ and Neonatal Medicine Hospital Clínic and Hospital Sant Joan de Déu, Universitat de Barcelona, Barcelona, Spain; \\ ${ }^{\mathrm{d}}$ Department of Obstetrics, Charite University Medicine Berlin, Berlin, Germany
}

\section{Key Words}

Angiogenesis - Uteroplacental insufficiency - Preeclampsia . Intrauterine growth restriction $\cdot$ Congenital heart defects

fers new clinical opportunities. This review summarizes the current knowledge of the pathophysiological implications and the clinical role of angiogenic factors in pregnancy.

ㄷ) 2015 S. Karger AG, Basel

\begin{abstract}
Angiogenic markers are now being incorporated into clinical practice for the screening, diagnosing, and monitoring of preeclampsia. Pregnancy requires both vasculogenesis and angiogenesis in the fetal compartment and angiogenesis in the maternal compartment. Abnormal angiogenesis in the placenta determines impaired remodeling of the maternal spiral arteries and placental underperfusion that may ultimately lead to fetal growth restriction and maternal preeclampsia. The dysregulation of angiogenesis in the placenta and maternal-fetal circulation has emerged as one of the main pathophysiological features in the development of placental insufficiency and its clinical consequences. Abnormal angiogenesis has also been related to other obstetric and fetal conditions such as peripartum cardiomyopathy and fetal cardiac defects. This opens up new challenges for our understanding of angiogenic involvement in maternal cardiovascular function and fetal cardiac development, and it of-
\end{abstract}

\section{KARGER 125}

(c) 2015 S. Karger AG, Basel

1015-3837/15/0372-0081\$39.50/0

E-Mail karger@karger.com

www.karger.com/fdt

\section{Physiological and Pathophysiological Roles in Humans in Pregnancy}

The Role of Endoglin, PlGF, VEGF, and sVEGFR-1 in Normal Placenta

Extravillous cytotrophoblasts invade the uterine spiral arteries of the decidua and myometrium in early normal embryonic development. Fetal cells replace the endothelial layer of uterine vessels, transforming them into highcapacity vessels that permit an increase in uterine blood flow.

Similar to tumor growth, a balance of pro-angiogenic and anti-angiogenic factors is established in the developing placenta [1]. The vascular endothelial growth factor (VEGF) family consists of VEGF-A, placental growth factor (PIGF), VEGF-B, VEGF-C, and VEGF-D; their receptors VEGF-I (also called fms-like-tyrosine-kinase receptor 
I, Flt-1), VEGFR-2 (also called kinase insert domain receptor, KDR), and VEGFR-3 (Flt-4); and their co-receptors, neuropilin-I (NRP-I) and NRP-2. The key molecules regulating early placental vascular changes are VEGF-A, PIGF, and the receptors Flt- 1 and KDR [2]. In addition to the two membrane-bound receptors, a splice variant of Flt-1, called soluble Flt-1 (sFlt-1), is expressed in the placenta and is known to have an anti-angiogenic effect.

Vasculogenesis and angiogenesis are two essential processes in the establishment of the utero-placental circulation when placental expressions of VEGF-A, Flt-1, and KDR are high and PlGF expression is moderate [3]. In vitro experiments have shown that binding of VEGF-A to Flt-1 and KDR stimulates branching angiogenesis [4]. PlGF, which is expressed in trophoblasts throughout gestation by acting on Flt-1, may play a supplementary role in vasculogenesis by recruiting macrophages. From 25 weeks of gestation, angiogenesis switches from branching to non-branching and is accompanied by a decline in VEGF-A and KDR and an increase in the expression of PlGF, Flt-1, and sFlt-1. PlGF may have a role in nonbranching angiogenesis that continues until term [5].

\section{Angiogenesis Imbalance in Placental Vascular Impairment and Underperfusion}

Both preeclampsia (PE) and intrauterine growth restriction (IUGR) are associated with pathogenic evidence of placental underperfusion and ischemia [6], including acute atherosis, intimal thickening, necrosis, atherosclerosis and endothelial damage, and placental infarction. In these cases, there is impairment of the perivascular and endovascular trophoblastic invasion into the spiral arteries that fail to become low-resistance vessels [7]. Abnormal angiogenesis in the placenta determines impaired remodeling of the maternal spiral arteries and placental underperfusion that may ultimately lead to fetal growth restriction and maternal preeclampsia [8-10]. Evidence shows that angiogenic factors are important in the regulation of placental vasculogenesis.

VEGF, PlGF, and Flt 1 are highly expressed by invasive cytotrophoblasts, and it has been shown that their expression is altered in placenta tissue of women with preeclampsia and that sFlt1 reduces cytotrophoblast invasiveness in vitro [11]. In addition, mice deficient in these receptors have impaired vascular development and die in utero. Moreover, recent studies in an animal model of spontaneous preeclampsia (BPH/5 mice) showed that adenoviral-mediated delivery of VEGF early in pregnancy prevents the spontaneous development of preeclampsia and incidence of fetal resorptions [12].
The factors regulating sFlt1 and sEng expression are just beginning to be elucidated. It has been suggested that abnormal oxygen tension and the hypoxia reoxygenation caused by intermittent perfusion-reperfusion can cause oxidative stress [13]. It has been shown that this feature is likely to trigger apoptosis, release of sFlt1 and sEng and pro-inflammatory cytokines such as IL-6 (fig. 1). In addition to this, in women with pre-eclampsia, a lower HO-1 activity has been observed and it may mediate increased sFlt1 and sFlt1 activity $[14,15]$.

\section{Maternal Consequences of Angiogenesis Deregulation}

\section{Endothelial Dysfunction and PE}

The Two-Stage Model of preeclampsia proposes that a poorly perfused placenta (Stage 1) produces factor(s) leading to the clinical manifestations of preeclampsia [16] (Stage 2). However, the cause of impaired vascular remodeling occurs earlier in pregnancy. Therefore, we suggest preeclampsia as a three-stage model (fig. 1).

There is experimental evidence that supports the hypothesis that interference with VEGF/PlGF signaling could mediate endothelial dysfunction in preeclampsia. VEGF is important in the stabilization of endothelial cells in mature blood vessels. Organs severely affected by preeclampsia, renal glomerulus, brain, and liver, are characterized by a fenestrated endothelium and VEGF regulation is especially important in these kind of vessels. VEGF signals through two major receptors: Flk and Flt1. Placental expression of sFlt1 is increased in PE, and it is associated with a marked increase in maternal circulating sFlt1 levels [17]. sFlt1 antagonizes both VEGF and PlGF by binding them in the circulation and preventing interaction with their endogenous receptors [18, 19] (fig. 2). In vitro effects of sFlt1 include vasoconstriction and endothelial dysfunction. Studies in gravid mice demonstrated that either with the direct injection of the protein or by injecting adenovirus expressing the sFlt messenger, RNA produces hypertension, proteinuria, and glomerular endotheliosis [20]. Moreover, other experiments, which reduced uterine perfusion, increased circulating and placental sFlt1 [21]. Reduction in circulating soluble Flt-1 alleviated pre-eclampsia-like symptoms in a mouse model [22]. Therefore, over-expression of sFlt1 is a key feature that links placental dysfunction and endothelial disease.

$\mathrm{PlGF}$ is also an important contributor to endothelial dysfunction, although its physiological role is less understood. It is thought to amplify VEGF signaling by dis- 
Fig. 1. Preeclampsia is a three-stage disorpression of pro-angiogenic factors (VEGF and PlGF) and hypoxia-inducible factors (HO1) triggers abnormal remodeling of spiral arteries and trophoblast invasion (Stage 1). Impaired placental perfusion leads to hypoxia and oxidative damage (Stage 2). Pathologic placenta induces apoptosis, inflammation, and release of anti-angiogenic factors (sFlt1 and sEnd) that promote systemic endothelial dysfunction, with vasoconstriction and end-organ ischemia, that finally leads to preeclampsia sings and syntoms (Stage 3 ). der: In preeclamptic decidua, deficient ex-

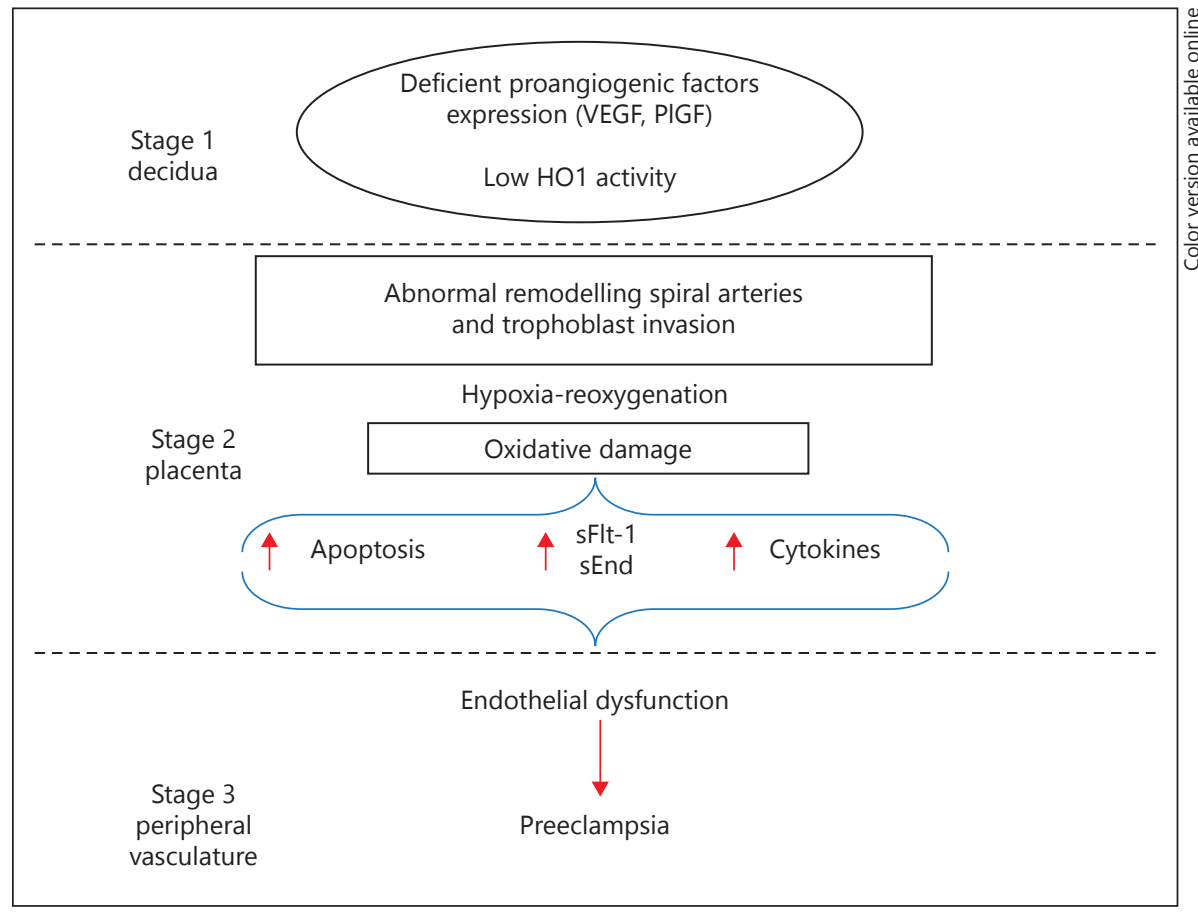

Fig. 2. sFlt1 and sEnd caused endothelial dysfunction by antagonizing VEGF and TGF- $\beta 1$ signaling in the vasculature. During normal pregnancy, endothelial synthesis of protacyclin and expression of nitric oxide is enhanced by physiological levels of VEGF and TGF- $\beta$ throughout their receptors. In preeclampsia, high levels of circulating sFlt1 and sEnd bind VEGF and TGF- $\beta$, antagonizing their actions and resulting in endothelial dysfunction (adapted from Karumanchi SA, Epstein FH: Placental ischemia and soluble fms-like tyrosine kinase 1: cause or consequence of preeclampsia? Kidney Int 2007;71:959-961.).
Normal pregnancy

Extracellular space

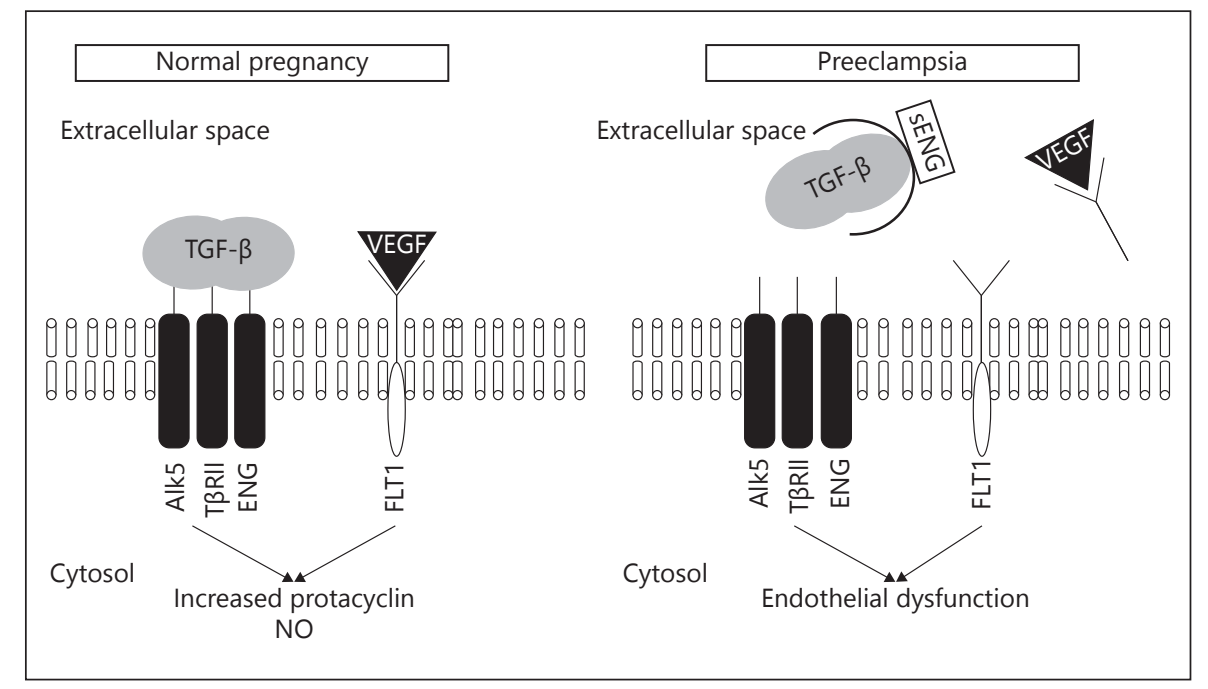

placing VEGF from the Flt1 receptor and instead allowing it to bind to the more potent KDR receptor. During pregnancy, inhibition of both PIGF and VEGF is necessary to produce preeclampsia-like changes in pregnant rats. Soluble endoglin, a truncate form of endoglin, which binds and antagonizes TGF- $\beta$, is up-regulated in preeclampsia. In pregnant rats, sEnd amplifies the vascular damage mediated by sFlt1 [20]. The inhibition of
TGR- $\beta$ and VEGF signaling in the vasculature results in endothelial dysfunction, including decreased prostacyclin, nitric oxide production, and release of pro-coagulant proteins (fig. 2).

\section{Later Cardiovascular Risk}

The cardiovascular implications of preeclampsia do not end with the birth of the infant and placenta. 
Common risk factors between CVD and preeclampsia lead us to hypothesize that increased CVD in women after preeclampsia is the result of pre-existing conditions. Multiple studies and meta-analysis confirm that women, whose pregnancy was complicated by preeclampsia, have higher susceptibility to CVD later in life. Whether preeclampsia directly influences the development of maternal cardiovascular disease later in life or preeclampsia uncovers a pre-existing condition that could lead to CVS later in life anyway remains undetermined [23].

Women with preeclampsia have markedly abnormal cardiac function $[24,25]$. It has been shown that myocardial performance index (MPI) correlated with levels of circulating sFlt1, whereas elevated blood pressure (BP) was not associated with MPI in women with preeclampsia. Therefore, these authors suggested that elevated sFlt1 causes the diastolic dysfunction in preeclampsia [26]. At 1 year postpartum, asymptomatic left ventricular moderate-severe dysfunction or hypertrophy was significantly higher in preterm preeclampsia (56\%) compared with term preeclampsia $(14 \%)$ or matched controls $(8 \%)$. The risk of developing essential hypertension within 2 years was significantly higher in both preterm preeclamptic women and those with persistent left ventricular moderate-severe abnormal function/geometry [27].

Anti-VEGF therapies given to adult animals cause glomerular endothelial damage with proteinuria. Anti-angiogenic therapies, including antibodies that neutralize VEGF and small-molecule VEGF receptor inhibitors, are being increasingly used in the oncological and ophthalmological settings in which cardiomyopathy and heart failure have recently been recognized as major side effects $[28,29]$. Angiogenic factors are involved in the development of atherosclerosis and show pronounced changes during acute myocardial infarction (AMI). High sFlt-1 levels proved to be a good predictor of mortality during a 1-year follow-up of AMI, regardless of information provided by troponin $\mathrm{T}$ and $\mathrm{N}$-terminal pro-B-type natriuretic peptide (NT-proBNP) [30]. PlGF has emerged as a central mediator in both coordination of cardiomyocyte growth and neo-angiogenesis [31]. Genetic and pharmacological studies identified PlGF as a novel cardioprotective factor [14].

Peripartum cardiomyopathy (PPCM) is characterized by systolic heart failure presenting in the last month of pregnancy and the first months post-partum. Half of these women with PPCM progress to chronic heart failure, cardiac transplantation, or death. Women who develop preeclampsia or multiple gestations are known risk factors. Patten et al. have recently associated PPCM with a systemic angiogenic imbalance [26]. At 4-6 weeks postpartum, women who developed PPMC had higher levels of sFlt1, remaining till 5- or 10-fold higher than the levels in control women.

Overall, these studies indicated that an anti-angiogenic state could be harmful to the human heart. Further studies are necessary to ascertain the contribution of angiogenic status during pregnancy to cardiovascular disease later in life.

\section{Prediction of Complications of Placental Disease}

\section{Evidence of Prediction of Preeclampsia/IUGR/IUFD}

with Angiogenic Factors in the First and Second

Trimester of Pregnancy

Circulating levels of sFlt 1 and PlGF are altered several weeks before the onset of clinical disease and correlated with the severity of disease [32]. sFlt-1 concentrations seemed to be increased throughout gestation in women destined to develop PE, a significant difference usually detectable at 5-6 weeks before presentation [33]. Serum concentrations of PlGF tend to be lower in women who develop the disease, and therefore, sFlt1/PlGF ratio has been proposed as an index of angiogenic imbalance.

With the ability of sFlt-1 and PlGF to accurately diagnose the disease, many studies have focused on the use of the markers as early predictors. Here, different approaches have been addressed about when to test and which other biophysical tests to adjunct in order to reach a maximum detection rate for the later onset of the disease.

Many groups have shown that the serum measurement of sFlt-1 and PlGF and other factors such as soluble endoglin in the second trimester of pregnancy allow for a precise prediction of the later onset of the disease [34-36]. Differences in asymptomatic patients who develop these complications with regard to healthy pregnancies are considerably more pronounced in early-onset cases, whereas in late-onset disease there is a substantial overlap with controls [37] (fig. 3).

The predictive value of sFlt1, PlGF, and sEng for the prediction of $\mathrm{PE}$ has consistently been demonstrated in the second trimester of pregnancy. Several studies evaluated a combined approach with the Doppler sonography of the uterine artery in the second trimester. The sensitivity and positive predictive value of uterine artery Doppler, known to be low, has been shown to increase when combined with measurement of angiogenic and anti-angiogenic factors [38, 39]; the combination of angiogenic factors and uterine artery Doppler at 20-24 weeks of ges- 


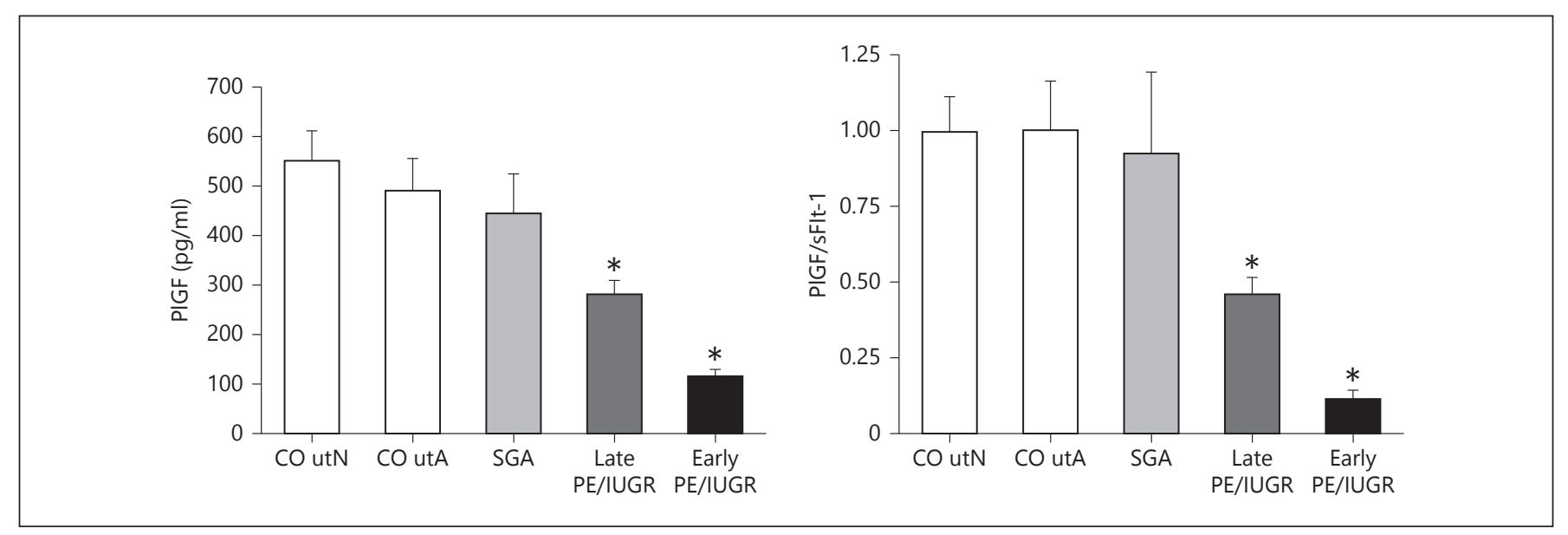

Fig. 3. PlGF (pg/ml) levels and PlGF/sFlt1 ratio in asymptomatic patients at 20-24 weeks of gestation according to pregnancy outcomes (CO utN $=$ Healthy patients with normal uterine artery Doppler; $\mathrm{CO}$ utA = healthy patients with abnormal uterine artery Dop- pler at 20 weeks of gestation; SGA = small for gestational age cases; Late PE/IUGR = late preeclampsia or/and IUGR cases; Early PE/ IUGR $=$ early preeclampsia or/and IUGR cases). ${ }^{*} \mathrm{p}<0.05 \mathrm{com}-$ pared with $\mathrm{CO}$ utN and $\mathrm{CO}$ utA and SGA cases (ANOVA test). tation have $89.5 \%$ sensitivity with $95 \%$ specificity for identifying early-onset preeclampsia. Conversely, the sensitivity for late-onset PE was below 11\% [37]. These observations are in line with the idea that late-onset PE constitutes a heterogeneous condition with either minimal or no placental involvement, and, therefore, tests based on the identification of signs of abnormal placentation are of limited value in predicting this entity. In addition to these, the group consisting of Roberto Romero and others has highlighted the importance of repeated measurements, as the slope of the markers indicates those at risk for the condition [40-42].

The evidence from meta-analysis shows that prevention of preeclampsia with low-dose aspirin may be possible if treatment is started before 16 weeks of gestation [43]. The efforts for the prediction of preeclampsia have shifted from the second to the first trimester of pregnancy. Data on PlGF occur early in the first trimester and have been tested alone or in combination with other biomarkers as a potential predictive test. Recently, the group of Kypros Nicolaides has evaluated the ability of serum markers to predict preeclampsia already in the first trimester. In an combined screening approach, he has shown that a combination of maternal history, uterine artery Doppler, blood pressure measurement, and the serum measurement of PAPP-A and PlGF is able to detect the later onset of early-onset preeclampsia with a sensitivity till $93 \%$ at a false-positive rate till $5 \%[4,44-46]$. Recent data showed that not only PlGF but also sFlt-1 substantially improved the prediction for late PE [47].

Angiogenic Factors in Pregnancy
Usefulness of Angiogenic Factors in the Third

Trimester of Pregnancy for Adverse Outcomes

Most efforts have been concentrated in predicting early PE/IUGR, as it denotes the highest severity. However, most cases of PE and IUGR occur at or near term, including a substantial proportion of maternal morbidity and medically indicated late preterm births [48-50]. Consequently, late PE and IUGR and its early prediction/diagnosis represent a public healthcare priority.

First- and second-trimester strategies show poorer predictive values for late-onset forms of PE and IUGR [51-57]. This may be explained by the milder nature of the disease, where changes can possibly not be picked up that early in gestation, together with the heterogeneity of these clinical conditions late in pregnancy. However, a different approach that comes closer in time to the onset of the disease could improve the detection rates.

\section{Evidences for Angiogenic Factors in Third-Trimester Screening of Late PE}

Recent studies have shown a potential utility of angiogenic factors for the third-trimester prediction of late PE. Chaiworapongsa et al. demonstrated that maternal plasmatic concentrations of $\mathrm{PlGF} / \mathrm{sEng}<0.3 \mathrm{MoM}$ at $30-34$ weeks of gestation have been demonstrated to be associated with late PE (adjusted odds ratio 7) and severe late PE (adjusted odds ratio 16 ), leading to a sensitivity of $74 \%$ for severe late $\mathrm{PE}$ with a false-positive rate of $15 \%$ [54]. The addition of PlGF/sEng to clinical risk factors increased the area under the receiver-operating characteristic curve from 
0.76 to 0.88 . Predictive values in the third trimester for late $\mathrm{PE}$ are superior to those achieved in the first or second trimester of pregnancy. In addition, several studies from the Fetal Medicine Foundation $[55,56]$ have also evaluated the predictive value of angiogenic factors together with maternal characteristics and uterine Doppler in the third trimester for late PE. A combination of maternal characteristics and serum PlGF had a detection rate of 86 and $53 \%$ for intermediate PE (delivery at 34-37 weeks) and late PE (delivery after 37 weeks), with a $10 \%$ false-positive rate.

\section{Placental Underperfusion and Maternal PlGF in IUGR}

Intrauterine growth restriction is defined as a failure to achieve the endorsed growth potential and is usually diagnosed by birthweight below the 10th centile. A clinically relevant issue is the distinction of 'true' IUGR, associated with placental insufficiency, poorer perinatal and long-term outcome from constitutional small-forgestational age [57]. It is well known that patients with IUGR are often associated with preeclampsia and exhibit an anti-angiogenic profile [58-60]. The levels of sFlt-1/ PlGF-ratio in early-onset IUGR are significantly different from those of controls, as several clinical studies have shown. A dysfunctional placenta is the origin of a risk for either mother and/or fetus. However, it is unknown as to which women with a dysfunctional placenta 'only' develop a fetal syndrome and which will develop maternal disease termed preeclampsia. Assessment of angiogenic and anti-angiogenic factors, however, might determine those at risk for complications [61].

Recent studies $[62,63]$ suggest that differences in maternal PlGF concentrations may have the ability to discriminate between fetuses with placental IUGR and constitutionally small fetuses. Placental vascular insufficiency in late pregnancy may be anticipated by maternal low detectable PIGF levels on discovery of SGA status. Actually, Triunfo et al. [62] demonstrated that maternal PlGF is an independent predictor of placental underperfusion in IUGR. Therefore, angiogenic factors may be pivotal in identifying small fetuses with placental underperfusion and true growth restriction. Future studies are warranted to assess how incorporating these factors into the current clinical criteria defines late-onset IUGR due to placental insufficiency.

\section{Maternal PlGF for the Detection of Perinatal}

Complications in IUGR

Once the diagnosis of IUGR is established, a second clinically relevant step in IUGR is management and deci- sion on the optimal timing to finalize the pregnancy. For that aim, it is critical to adequately select those IUGR cases at risk of perinatal complications. Despite most research focalized in feto-placental Doppler, recent data also suggest that angiogenic factors could help in the prediction of complications among IUGR cases. Maternal angiogenic imbalance (lower PlGF and higher sFlt1/ PlGF) has shown a significant association with neonatal metabolic acidosis and operative delivery for non-reassuring fetal status. Lobmaier et al. [64] demonstrated a similar performance of maternal PlGF and feto-placental Doppler for the early detection of perinatal complications in IUGR, concluding that maternal angiogenic factors at diagnosis and follow-up with Doppler predict adverse outcomes with a similar performance. This information may be of help in tailoring surveillance and identifying late-onset FGR fetuses who may benefit from elective delivery at term.

Overall, the evidence showing an association among maternal angiogenic factors, placental underperfusion, and adverse perinatal outcome in IUGR supports the future incorporation of PlGF in the clinical protocols for diagnosing and managing IUGR fetuses. The use of angiogenic biomarkers for early identification and risk stratification has a strong potential to reduce both morbidity and healthcare costs in the management of IUGR fetuses.

\section{Evidence for Angiogenic Factors in Third-Trimester Screening for Late IUGR}

There is evidence that maternal concentrations of $\mathrm{PlGF} / \mathrm{sFlt1}$ and PlGF/sEng are associated with a significant increase in the likehood of development of SGA. Although a recent work could not demonstrate maternal angiogenic factors improving the identification of IUGR from the models using clinical factors [54], future studies are warranted to assess their potential predictive value in an integrated third-trimester screening for FGR.

\section{Evidence for Angiogenic Factors in Third-Trimester Screening for Late Stillbirth}

Promising recent data suggest that very low values of maternal plasmatic PlGF/sFlt1 $(<0.12 \mathrm{MoM})$ have a strong association with subsequent stillbirth, leading to $80 \%$ sensitivity and $93 \%$ sensitivity for detecting late stillbirth [54].

Overall, a third-trimester approach has demonstrated a high predictive value for late complications when compared with first- and second-trimester strategies. Identification of high-risk cases, even in third trimester, might
Llurba/Crispi/Verlohren 
have a huge impact on maternal and perinatal outcomes. Selection of high-risk subgroups might allow exploring the impact of strategies of targeted customized follow-up, or clinical trials evaluating the benefits (and risks) of elective delivery at term. Future studies will need to define the best combination of clinical, ultrasonographic, and biochemical factors in an integrated third-trimester screening for late complications of placental disease.

\section{Clinical Role in the Diagnosis and Prediction of \\ Adverse Outcomes in IUGR}

Angiogenic factors have a major role in vasculogenesis and angiogenesis in the placenta. An imbalance in angiogenic factors is impaired angiogenesis, placental development, and IUGR. As angiogenic factors are very closely related to placental disease and IUGR, recent studies have evaluated the potentiality of maternal PlGF/sFlt1 for assessing severity and predicting the risk of adverse perinatal outcome in IUGR pregnancies.

\section{Clinical Role in the Diagnosis and Management of Preeclampsia}

\section{Angiogenic Factors in the Diagnosis of PE}

The gold standard for preeclampsia diagnosis is the measurement of blood pressure and proteinuria. Clinicians and researchers alike are aware of the fact that this 'gold standard' is merely a surrogate definition [65]. It relies on the presence of a vague set of signs and symptoms to diagnose a multisystem disorder that may progress to severe complications involving end-organ damage. The pioneering work by Robertson, Brosens et al., published in 1967 has first shown the central role of the placenta in the etiology of the condition [66]. The knowledge about the impact of a failure in trophoblast invasion and defective spiral artery remodeling in preeclampsia has increased tremendously during the past decade due to meticulous research in that field [67-69]. This understanding, however, is not yet reflected in the clinical definition of the disease.

The current definitions for preeclampsia are poor in predicting preeclampsia-related adverse outcomes. Zhang et al. have shown that a diagnosis of preeclampsia based on blood pressure measurement and assessment of proteinuria has a positive predictive value of approximately $30 \%$ in predicting preeclampsia-related adverse outcomes [70]. At a time when suspicion of preeclampsia prompted renal biopsies to detect the preeclampsia defining lesion glomerular endotheliosis, studies have shown

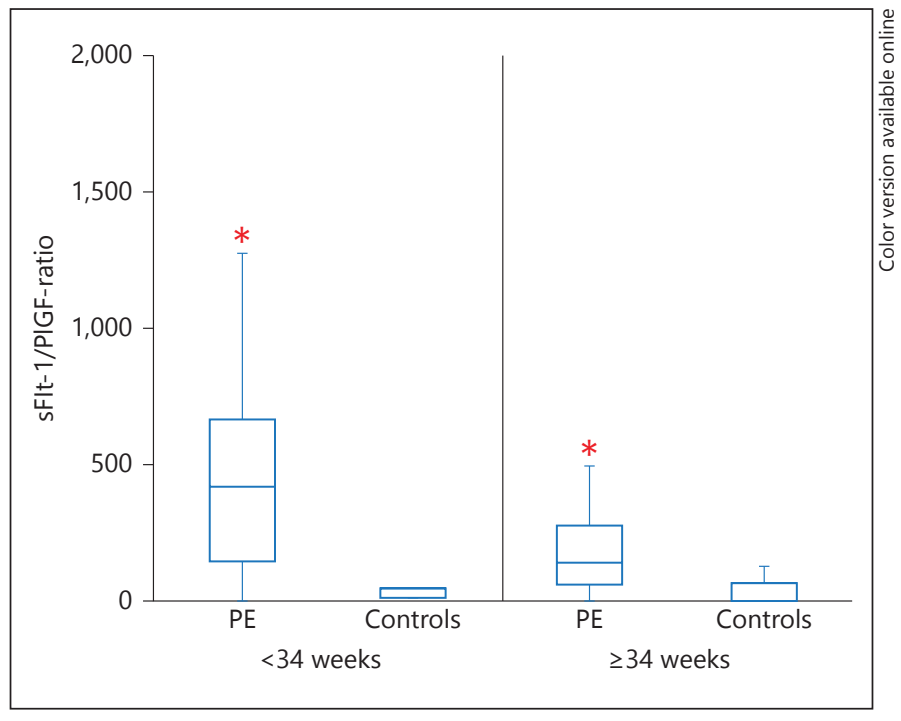

Fig. 4. Maternal serum sFlt-1/PlGF-ratio in early-onset versus lateonset preeclampsia: patients with early-onset preeclampsia $<34$ weeks of gestation have a significantly elevated sFlt-1/PlGF-ratio as compared with gestational age-matched patients with uneventful pregnancy outcomes. The same holds true for late-onset preeclampsia $>34$ weeks as compared with late controls. ${ }^{*} \mathrm{p}<0.05$. $\mathrm{PE}=$ Preeclampsia; sFlt -1 = soluble fms-like tyrosinkinase- 1 ; $\mathrm{PlGF}=$ placental growth factor: modified according to [78] .

that $20 \%$ of primipara and more than $30 \%$ of multipara were falsely classified as having preeclampsia based on the clinical definition [71].

The field of preeclampsia research has been shaken up by the discovery of the role of angiogenic and anti-angiogenic factors by the group of Ananth Karumanchi in 2003 [17]. Since these first publications, a multitude of clinical studies has established the ability of these markers to accurately diagnose and predict preeclampsia [72-76]. Meanwhile, automated tests are available to test for the condition in the clinical setting [77-79] (fig. 4). Recently, the results of a European multicenter study have been published while introducing new cut-offs for the sFlt-1/ PlGF-ratio in the clinical setting. It is now possible to diagnose preeclampsia with a sensitivity till $95 \%$ and a specificity till 99.5\% [80].

\section{Angiogenic Imbalance in the Prediction of Adverse \\ Outcomes in Women with Suspected PE}

Most clinical studies have chosen the endpoint preeclampsia according to the current definitions to evaluate new strategies for diagnosing or predicting the disease. However, from a clinical perspective, the question must be raised as to whether that endpoint is of any interest to 
the maternal-fetal medicine specialist in the clinic or the obstetrician in the delivery ward. In the end, the aim is to identify patients at risk for complications who are known to be associated with the presence of hypertension and proteinuria in pregnancy.

Rana et al. have recently shown that the sFlt-1/PlGFratio is able to predict preeclampsia-associated adverse outcomes with a high accuracy [81]. In a prospective multicenter study, they have enrolled 616 patients with signs and symptoms for preeclampsia. The endpoint of this study was not 'gold-standard preeclampsia' but the onset of preeclampsia-associated maternal or fetal adverse outcomes within two weeks. This was a composite outcome of either maternal complications such as a combination of hypertension and pulmonary edema, disseminated intravascular coagulation, and placental abruption (or else) or fetal complications such as indicated early delivery, fetal growth restriction, or fetal death. These patients who developed adverse outcomes have a significantly higher sFlt-1/PlGF-ratio with a median of 4 (25th-75th centile, $2-14)$ in patients without and a median of $226(50-547)$ in patients with early-onset preeclampsia-associated adverse outcomes. Furthermore, the authors were able to show that these patients who presented with an sFlt-1/ PlGF-ratio of more than 85 had a significantly reduced remaining pregnancy duration. The predictive accuracy for preeclampsia-associated complications was best for the sFlt-1/PlGF with an area under the receiver operating characteristics curve of 0.89 and significantly better than other clinical tools such as blood pressure or serum markers for HELLP syndrome such as alanine aspartate transferase. In twins, similar results were shown [82].

\section{Is There a Need to Revise Our Clinical Definition and} Management of Preeclampsia?

In the light of the increasing understanding of the central role of the placenta in the pathophysiology of preeclampsia, the current 'gold standard' of preeclampsia diagnosis must be revised. Till a few years ago, no biomarker was available to reliably assess the placental function in the clinical setting. Revising the gold standard does not simply mean to change the diagnostic criteria for 'preeclampsia'. Future interest must be directed toward a re-definition of this condition that is now called preeclampsia. Hypertension and proteinuria are just arbitrary markers for a syndrome that we did not have the means to previously describe better. Possibly, this newly defined disease will include a slightly different cohort of patients: those at risk for adverse outcomes. A cohort of patients who were diagnosed with increased blood pressure and proteinuria will not be classified at risk for adverse outcomes based on the measurements of the angiogenic factors, whereas others not fulfilling the current diagnostic criteria for preeclampsia will be based on their biochemical test result. It has been shown that patients with 'non angiogenic preeclampsia' are not at risk for adverse outcomes, whereas those with an increased sFlt-1/PlGF-ratio are at risk [83].

A limitation to this approach is the role of late-onset disease. Several authors have proposed a 'two disease theory' of preeclampsia, based on the clinical observation that early-onset preeclampsia has a predominant placental component and late-onset preeclampsia often coincides with preexisting maternal disease such as features of metabolic syndrome [84]. This dichotomization of placental (early onset) and maternal (late onset) preeclampsia is likely to be simplistic. The levels of angiogenic and antiangiogenic factors, however, are less disparate when comparing late-onset preeclamptic patients with term controls [85]. This again might relate to the nature of the (case-control) studies: new diagnostic markers have to be evaluated with the current gold standard. Hence, the 'control group' in these studies might be, in fact, a heterogeneous group involving patients with features of (late onset) placental dysfunction or decreasing placental function, as levels of sFlt-1 are higher and those of PlGF are lower in normal pregnant women near term than before 34 weeks. Likewise, the late-onset preeclampsia group without angiogenic dysbalance might not be a homogeneous group. When looking at birth weight as a proxy for placental function in late-onset preeclampsia patients, a bimodal, skewed distribution is observed, highlighting a component next to placental insufficiency in late-onset disease [86].

\section{Options for Treatment}

Till now, the only causative treatment for preeclampsia is delivery. In case of early-onset disease, this contributes to neonatal morbidity due to preterm delivery. The research on the pathophysiological role of the angiogenic imbalance for preeclampsia opened up the field for a novel therapeutical option. An excessive placental release and abundant serum concentration of sFlt-1 has been identified as a pacemaker of the disease. Ravi Thadhani and colleagues now hypothesized that lowering the circulating sFlt-1 concentrations in the maternal blood might ameliorate the disease and prolong pregnancy. With the use of dextran sulfate apheresis, a treatment method that has been previously shown to be safe and feasible in pregnancy for other indications such as familiar hypercholesterinemia [87], a removal of sFlt-1 from the maternal 
blood was performed. In a pilot study involving 8 women with severe early-onset preeclampsia, removal of sFlt-1 led to reduced proteinuria, stabilized blood pressure without any adverse events for mother and fetus. Most of all, a prolongation of pregnancy till 23 days was achieved [88]. If the results of this pilot study are confirmed by larger randomized trials, a therapeutic option for severe early-onset preeclampsia might contribute to an improvement of maternal and fetal preeclampsia-related morbidity and mortality.

\section{New Evidence in Congenital Cardiac Defects}

Animal studies [89-91] suggest that VEGF signaling plays a critical role throughout cardiac formation and that its levels must be tightly regulated for normal cardiac formation to occur [92]. Abnormal expression of angiogenenic markers in heart tissue of human fetuses with CHD has been demonstrated, which showed increased VEGF-A and sFlt-1 expression [93].

Moreover, in isolated major fetal heart defects, maternal serum PlGF levels at 11-13 weeks of gestation were decreased, suggesting impaired placental angiogenesis [94]. In addition, at 18-37 weeks of gestation, maternal serum PlGF was decreased and sFlt-1 was increased in women carrying a fetus with isolated major heart defects. In both studies, this angiogenic impairment was observed in the presence of conotruncal and septal-valve defects but not in the presence of left heart defects $[93,94]$. These findings suggest that abnormal angiogenesis may also be deleterious for embryogenesis of the human heart.

Further studies are warranted to ascertain whether these fetuses with CHD have an intrinsically altered angiogenesis, leading to an abnormal formation of the heart, that may be also present in trophoblastic cells or alternatively, low PlGF may be associated with a lesser degree of trophoblast invasion of the spiral arteries and therefore placental hypoxia that triggers abnormal heart development $[95,96]$.

\section{Conclusions}

The discovery of the role of angiogenic and anti-angiogenic factors in 2003 [17] has increased the acknowledgment of the pathophisiology of preeclampsia. This evidence leads to an exploration of the potential usefulness of angiogenic factors as markers for the prediction of the disease. The combination of maternal risk factors, angio- genic factors, and uterine artery Doppler velocimetry in the first trimester can predict subsequent development of early-onset preeclampsia with a sensitivity till $93 \%$ for a $5 \%$ false-positive rate. More recently, third-trimester screening has emerged as another important hallmark in the stratification of patient risk; thus, most cases of $\mathrm{PE}$ and IUGR occur at or near term, including a substantial proportion of maternal morbidity and medically indicated late preterm births. Angiogenic factors have also shown good sensitivity for the third-trimester prediction of late PE and stillbirth. Early estimation of patient-specific risks for preeclampsia and other placental insufficiency complications could potentially improve the outcome by directing such patients to specialist clinics for close surveillance and potentially, as well as early pharmacological interventions, such as aspirin, starting from the first trimester of pregnancy.

In the light of the increasing understanding of the central role of the placenta in the pathophysiology of preeclampsia, the question must be raised as to whether this information must be included in diagnostic algorithms. Future interest must be directed toward a re-definition of this condition that is now called preeclampsia. It is possible that angiogenic status would be useful to improve detection, define prognosis, and provide directions for best clinical management of hypertensive diseases of pregnancy and established preeclampsia.

Finally, angiogenic factors are also involved in other maternal pathologic conditions of pregnancy such as peri-partum cardiomiopaty and fetal cardiac defects. Abnormal angiogenesis in the heart tissue of human fetuses with CHD has been demonstrated. Moreover, in isolated major fetal heart defects, maternal serum PlGF levels were decreased and sFlt- 1 was increased in women carrying a fetus with isolated major heart defects. We believe that evaluating the relationship between CHD and placental-related complications is an important hypothesis to explore the subject of future research.

Future studies focusing on the regulation of angiogenic gene products and their role in placental angiogenesis and systemic vascular health will lead to a better understanding of the relationship between preeclampsia and fetal programming in intrauterine growth restriction with the development of cardiovascular disease [97].

\section{Disclosure Statement}

S.V. received consultancy payments and/or speaker fees from Roche Diagnostics and ThermoFisher.

E.L.L. and F.C. declare no conflicts of interest. 


\section{References}

-1 Romero R, Kusanovic JP, Chaiworapongsa T, Hassan SS: Placental bed disorders in preterm labor, preterm PROM, spontaneous abortion and abruptio placentae. Best Pract Res Clin Obstet Gynaecol 2011;25:313-327.

-2 Charnock-Jones DS, Kaufmann P, Mayhew TM: Aspects of human fetoplacental vasculogenesis and angiogenesis. I. Molecular regulation. Placenta 2004;25:103-113.

-3 Kaufmann P, Mayhew TM, Charnock-Jones DS: Aspects of human fetoplacental vasculogenesis and angiogenesis. II. Changes during normal pregnancy. Placenta 2004;25:114126.

-4 Wilting J, Birkenhager R, Eichmann A, Kurz H, Martiny-Baron G, Marme D, McCarthy JE, Christ B, Weich HA: VEGF121 induces proliferation of vascular endothelial cells and expression of flk-1 without affecting lymphatic vessels of chorioallantoic membrane. Dev Biol 1996;179:76-85.

$\checkmark 5$ Andraweera PH, Dekker GA, Roberts CT: The vascular endothelial growth factor family in adverse pregnancy outcomes. Hum Reprod Update 2012;18:436-457.

$\checkmark 6$ De Wolf F, De Wolf-Peeters C, Brosens I, Robertson WB: The human placental bed: electron microscopic study of trophoblastic invasion of spiral arteries. Am J Obstet Gynecol 1980;137:58-70.

7 Meekins JW, Pijnenborg R, Hanssens M, McFadyen IR, van Asshe A: A study of placental bed spiral arteries and trophoblast invasion in normal and severe pre-eclamptic pregnancies. Br J Obstet Gynaecol 1994;101:669-674.

$>8$ Shore VH, Wang TH, Wang CL, Torry RJ, Caudle MR, Torry DS: Vascular endothelial growth factor, placenta growth factor and their receptors in isolated human trophoblast. Placenta 1997;18:657-665.

9 Ziche M, Maglione D, Ribatti D: Placenta growth factor-1 is chemotactic, mitogenic, and angiogenic. Lab Invest 1997;76:517-531.

10 Akolekar R, Syngelaki A, Sarquis R, Zvanca $\mathrm{M}$, Nicolaides KH: Prediction of early, intermediate and late pre-eclampsia from maternal factors, biophysical and biochemical markers at 11-13 weeks. Prenat Diagn 2011; 31:66-74.

-11 Zhou Y, McMaster M, Woo K, Janatpour M, Perry J, Karpanen T, Alitalo K, Damsky C, Fisher SJ: Vascular endothelial growth factor ligands and receptors that regulate human cytotrophoblast survival are dysregulated in severe preeclampsia and hemolysis, elevated liver enzymes, and low platelets syndrome. Am J Pathol 2002;160:1405-1423.

$>12$ Woods AK, Hoffmann DS, Weydert CJ, Butler SD, Zhou Y, Sharma RV, Davisson RL: Adenoviral delivery of VEGF121 early in pregnancy prevents spontaneous development of preeclampsia in $\mathrm{BPH} / 5$ mice. Hypertension 2011;57:94-102.

-13 Burton GJ, Woods AW, Jauniaux E, Kingdom JC: Rheological and physiological conse- quences of conversion of the maternal spiral arteries for uteroplacental blood flow during human pregnancy. Placenta 2009;30:473482.

14 Cudmore M, Ahmad S, Al-Ani B, Fujisawa T, Coxall H, Chudasama K, Devey LR, Wigmore SJ, Abbas A, Hewett PW, Ahmed A: Negative regulation of soluble Flt-1 and soluble endoglin release by heme oxygenase- 1 . Circulation 2007;115:1789-1797.

15 Zhao H, Wong RJ, Kalish FS, Nayak NR, Stevenson DK: Effect of heme oxygenase-1 deficiency on placental development. Placenta 2009;30:861-868

16 Roberts J: Pre-eclampsia a two-stage disorder: what is the linkage? Are there directed fetal/ placental signals? In Lyall F, Belfort M (eds): Pre-Eclampsia: Etiology and Clinical Practice. New York, Cambridge University Press, 2007, pp 183-194.

$>17$ Maynard SE, Min JY, Merchan J, Lim KH, Li J, Mondal S, Libermann TA, Morgan JP, Sellke FW, Stillman IE, Epstein FH, Sukhatme VP, Karumanchi SA: Excess placental soluble fms-like tyrosine kinase 1 (sFlt1) may contribute to endothelial dysfunction, hypertension, and proteinuria in preeclampsia. J Clin Invest 2003;111:649-658.

18 Karumanchi SA, Epstein FH: Placental ischemia and soluble fms-like tyrosine kinase 1: cause or consequence of preeclampsia? Kidney Int 2007;71:959-961.

19 Kendall RL, Thomas KA: Inhibition of vascular endothelial cell growth factor activity by an endogenously encoded soluble receptor. Proc Natl Acad Sci U S A 1993;90:10705-10709.

20 Lu F, Longo M, Tamayo E, Maner W, AlHendy A, Anderson GD, Hankins GD, Saade GR: The effect of over-expression of sFlt-1 on blood pressure and the occurrence of other manifestations of preeclampsia in unrestrained conscious pregnant mice. Am J Obstet Gynecol 2007;196:396.e1-e7.

21 Gilbert JS, Babcock SA, Granger JP: Hypertension produced by reduced uterine perfusion in pregnant rats is associated with increased soluble fms-like tyrosine kinase- 1 expression. Hypertension 2007;50:1142-1147.

$>22$ Bergmann A, Ahmad S, Cudmore M, Gruber AD, Wittschen P, Lindenmaier W, Christofori G, Gross V, Gonzalves ACh, Gröne HJ, Ahmed A, Weich HA: Reduction of circulating soluble Flt-1 alleviates preeclampsia-like symptoms in a mouse model. J Cell Mol Med 2010;14:1857-1867.

23 Romundstad PR, Magnussen EB, Smith GD, Vatten LJ: Hypertension in pregnancy and later cardiovascular risk: common antecedents? Circulation 2010;122:579-584.

24 Tei C, et al: New index of combined systolic and diastolic myocardial performance: a simple and reproducible measure of cardiac function - a study in normals and dilated cardiomyopathy. J Cardiol 1995;26:357366.
25 Kasner M, et al: Utility of Doppler echocardiography and tissue Doppler imaging in the estimation of diastolic function in heart failure with normal ejection fraction: a comparative Doppler-conductance catheterization study. Circulation 2007;116:637-647.

26 Patten IS, Rana S, Shahul S, Rowe GC, Jang C, Liu L, Hacker MR, Rhee JS, Mitchell J, Mah$\operatorname{mood}$ F, Hess P, Farrell C, Koulisis N, Khankin EV, Burke SD, Tudorache I, Bauersachs J, del Monte F, Hilfiker-Kleiner D, Karumanchi SA, Arany Z: Cardiac angiogenic imbalance leads to peripartum cardiomyopathy. Nature 2012;485:333-338.

27 Melchiorre K, Sutherland GR, Liberati M, Thilaganathan B: Preeclampsia is associated with persistent postpartum cardiovascular impairment. Hypertension 2011;58:709-715.

28 Kirk R: Bevacizumab and heart failure. Nat Rev Clin Oncol 2011;8:124.

29 Uraizee I, Cheng S, Moslehi J: Reversible cardiomyopathy associated with sunitinib and sorafenib. N Engl J Med 2011;365:1649-1650.

30 Hochholzer W, Reichlin T, Stelzig C, Hochholzer K, Meissner J, Breidthardt T, Reiter M, Duehsler B, Freidank H, Winkler K, Twerenbold R, Mueller C: Impact of soluble fms-like tyrosine kinase-1 and placental growth factor serum levels for risk stratification and early diagnosis in patients with suspected acute myocardial infarction. Eur Heart J 2011;32: 326-335.

31 Carmeliet P, Moons L, Luttun A, Vincenti V, Compernolle V, De Mol M, Wu Y, Bono F, Devy L, Beck H, Scholz D, Acker T, DiPalma T, Dewerchin M, Noel A, Stalmans I, Barra A, Blacher S, VandenDriessche T, Ponten A, Eriksson U, Plate KH, Foidart JM, Schaper W, Charnock-Jones DS, Hicklin DJ, Herbert JM, Collen D, Persico MG: Synergism between vascular endothelial growth factor and placental growth factor contributes to angiogenesis and plasma extravasation in pathological conditions. Nat Med 2001;7:575-583.

32 Levine RJ, Lam C, Qian C, Yu KF, Maynard SE, Sachs BP, Sibai BM, Epstein FH, Romero R, Thadhani R, Karumanchi SA; CPEP Study Group: Soluble endoglin and other circulating antiangiogenic factors in preeclampsia. $\mathrm{N}$ Engl J Med 2006;355:992-1005.

>33 Noori M, Donald AE, Angelakopoulou A, Hingorani AD, Williams DJ: Prospective study of placental angiogenic factors and maternal vascular function before and after preeclampsia and gestational hypertension. Circulation 2010;122:478-487.

34 Romero R, Nien JK, Espinoza J, et al: A longitudinal study of angiogenic (placental growth factor) and anti-angiogenic (soluble endoglin and soluble vascular endothelial growth factor receptor-1) factors in normal pregnancy and patients destined to develop preeclampsia and deliver a small for gestational age neonate. J Matern Fetal Neonatal Med 2008;21: 9-23. 
-35 De Vivo A, Baviera G, Giordano D, Todarello G, Corrado F, D'Anna R: Endoglin, PlGF and sFlt-1 as markers for predicting pre-eclampsia. Acta Obstet Gynecol Scand 2008;87:837842.

-36 Moore Simas TA, Crawford SL, Solitro MJ, Frost SC, Meyer BA, Maynard SE: Angiogenic factors for the prediction of preeclampsia in high-risk women. Am J Obstet Gynecol 2007; 197:244.e1-e8.

- 37 Crispi F, Llurba E, Domínguez C, MartínGallán P, Cabero L, Gratacós E: Predictive value of angiogenic factors and uterine artery Doppler for early- versus late-onset pre-eclampsia and intrauterine growth restriction. Ultrasound Obstet Gynecol 2008;31:303309.

- 38 Stepan H, Geipel A, Schwarz F, Kramer T, Wessel N, Faber R: Circulatory soluble endoglin and its predictive value for preeclampsia in second-trimester pregnancies with abnormal uterine perfusion. Am J Obstet Gynecol 2008;198:175.e1-e6.

- 39 Espinoza J, Romero R, Nien JK, et al: Identification of patients at risk for early onset and/ or severe preeclampsia with the use of uterine artery Doppler velocimetry and placental growth factor. Am J Obstet Gynecol 2007;196: 326.e1-e13.

40 Crispi F, Domínguez C, Llurba E, MartínGallán P, Cabero L, Gratacós E: Placental angiogenic growth factors and uterine artery Doppler findings for characterization of different subsets in preeclampsia and in isolated intrauterine growth restriction. Am J Obstet Gynecol 2006; 195:201-207.

-41 Chaiworapongsa T, Romero R, Kim YM, et al: Plasma soluble vascular endothelial growth factor receptor-1 concentration is elevated prior to the clinical diagnosis of pre-eclampsia. J Matern Fetal Neonatal Med 2005;17:318.

42 Erez O, Romero R, Espinoza J, et al: The change in concentrations of angiogenic and anti-angiogenic factors in maternal plasma between the first and second trimesters in risk assessment for the subsequent development of preeclampsia and small-for-gestational age. J Matern Fetal Neonatal Med 2008;21: 279-287.

43 Bujold E, Roberge S, Lacasse Y, Bureau M, Audibert F, Marcoux S, Forest JC, Giguère Y: Prevention of preeclampsia and intrauterine growth restriction with aspirin started in early pregnancy: a meta-analysis. Obstet Gynecol 2010;116:402-414.

44 Poon LC, Kametas NA, Maiz N, Akolekar R, Nicolaides KH: First-trimester prediction of hypertensive disorders in pregnancy. Hypertension 2009;53:812-818.

-45 Wright D, Akolekar R, Syngelaki A, Poon LC, Nicolaides KH: A competing risks model in early screening for preeclampsia. Fetal Diagn Ther 2012;32:171-178.

46 Poon LC, Akolekar R, Lachmann R, Beta J, Nicolaides KH: Hypertensive disorders in pregnancy: screening by biophysical and bio- chemical markers at 11-13 weeks. Ultrasound Obstet Gynecol 2010;35:662-670.

47 Crovetto F, Figueras F, Triunfo S, Crispi F, Rodriguez-Sureda V, Peguero A, Dominguez C, Gratacos E: Added value of angiogenic factors for the prediction of early and late preeclampsia in the first trimester of pregnancy. Fetal Diagn Ther 2014;35:258-266.

48 Berg CJ, Callaghan WM, Syverson C, Henderson Z: Pregnancy-related mortality in the United States, 1998 to 2005. Obstet Gynecol 2010;116:1302-1309.

49 Zhang J, Meikle S, Trumble A: Severe maternal morbidity associated with hypertensive disorders in pregnancy in the United States. Hypertens Pregnancy 2003;22:203-212.

-50 Crispi F, Dominguez C, Llurba E, MartinGallan P, Cabero L, Gratacos E: Placental angiogenic growth factors and uterine artery Doppler findings for characterization of different subsets in preeclampsia and in isolated intrauterine growth restriction. Am J Obstet Gynecol 2006;195:201-207.

51 Poon LC, Syngelaki A, Akolekar R, Lai J, Nicolaides KH: Combined screening for preeclampsia and small for gestational age at 1113 weeks. Fetal Diagn Ther 2013;33:16-27.

52 Scazzocchio E, Figueras F, Crispi F, Meler E, Masoller N, Mula R, Gratacos E: Performance of a first-trimester screening of preeclampsia in a routine care low-risk setting. Am J Obstet Gynecol 2013;208:203.e1-e10.

53 Crovetto F, Crispi F, Scazzocchio E, Mercade I, Meler E, Figueras F, Gratacos E: First-trimester screening for early and late small-forgestational-age neonates using maternal serum biochemistry, blood pressure and uterine artery Doppler. Ultrasound Obstet Gynecol 2014;43:34-40.

54 Chaiworapongsa $\mathrm{T}$, Romero R, Korzeniewski SJ, Kusanovic JP, Soto E, Lam J, Dong Z, Than NG, Yeo L, Hernandez-Andrade E, CondeAgudelo A, Hassan SS: Maternal plasma concentrations of angiogenic/antiangiogenic factors in the third trimester of pregnancy to identify the patient at risk for stillbirth at or near term and severe late preeclampsia. Am J Obstet Gynecol 2013;208:287.e1-e15.

55 Lai J, Pinas A, Poon LC, Agathokleous M, Nicolaides KH: Maternal serum placental growth factor, pregnancy-associated plasma protein-A and free $\beta$-human chorionic gonadotrophin at 30-33 weeks in the prediction of pre-eclampsia. Fetal Diagn Ther 2013;33: 164-172.

56 Lai J, Syngelaki A, Poon LC, Nucci M, Nicolaides KH: Maternal serum soluble endoglin at 30-33 weeks in the prediction of preeclampsia. Fetal Diagn Ther 2013;33:149155.

7 Figueras F, Gratacós E: Update on the diagnosis and classification of fetal growth restriction and proposal of a stage-based management protocol. Fetal Diagn Ther 2014;36:8698.

58 Gomez-Arriaga PI, Herraiz I, Lopez-Jimenez EA, Gomez-Montes E, Denk B, Galindo A:
Uterine artery Doppler and sFlt-1/PlGF ratio: usefulness in diagnosis of pre-eclampsia. Ultrasound Obstet Gynecol 2013;41:530-537.

59 Schlembach D, Wallner W, Sengenberger R, et al: Angiogenic growth factor levels in maternal and fetal blood: correlation with Doppler ultrasound parameters in pregnancies complicated by pre-eclampsia and intrauterine growth restriction. Ultrasound Obstet Gynecol 2007;29:407-413.

60 Herraiz I, Dröge LA, Gómez-Montes E, Henrich W, Galindo A, Verlohren S: Characterization of the soluble fms-like tyrosine kinase- 1 to placental growth factor ratio in pregnancies complicated by fetal growth restriction. Obstet Gynecol 2014;124:265-273.

61 Stepan H, Krämer T, Faber R: Maternal plasma concentrations of soluble endoglin in pregnancies with intrauterine growth restriction. J Clin Endocrinol Metab 2007;92:28312834.

62 Triunfo S, Lobmaier S, Parra-Saavedra M, Crovetto F, Peguero A, Nadal A, Gratacos E, Figueras F: Angiogenic factors at diagnosis of late-onset small-for-gestational age and histological placental underperfusion. Placenta 2014;35:398-403.

63 Benton SJ, Hu Y, Xie F, Kupfer K, Lee SW, Magee LA, von Dadelszen P: Can placental growth factor in maternal circulation identify fetuses with placental intrauterine growth restriction? Am J Obstet Gynecol 2012;206:163. e1-e7.

64 Lobmaier SM, Figueras F, Mercade I, Perello M, Peguero A, Crovetto F, Ortiz JU, Crispi F, Gratacós E: Angiogenic factors vs Doppler surveillance in the prediction of adverse outcome among late-pregnancy small-for-gestational-age fetuses. Ultrasound Obstet Gynecol 2014;43:533-540

65 Staff AC, Benton SJ, von Dadelszen P, et al: Redefining preeclampsia using placenta-derived biomarkers. Hypertension 2013;61: 932-942.

66 Robertson WB, Brosens I, Dixon HG: The pathological response of the vessels of the placental bed to hypertensive pregnancy. J Pathol Bacteriol 1967;93:581-592.

67 Khong TY, De Wolf F, Robertson WB, Brosens I: Inadequate maternal vascular response to placentation in pregnancies complicated by pre-eclampsia and by small-for-gestational age infants. Br J Obstet Gynaecol 1986;93: 1049-1059.

68 Zhou Y, Fisher SJ, Janatpour M, et al: Human cytotrophoblasts adopt a vascular phenotype as they differentiate. A strategy for successful endovascular invasion? J Clin Invest 1997;99: 2139-2151.

69 Pijnenborg R, Anthony J, Davey D, et al: Placental bed spiral arteries in the hypertensive disorders of pregnancy. Br J Obstet Gynaecol 1991;98:648-655.

70 Zhang J, Klebanoff MA, Roberts JM: Prediction of adverse outcomes by common definitions of hypertension in pregnancy. Obstet Gynecol 2001;97:261-267. 
-71 Fisher KA, Luger A, Spargo BH, Lindheimer MD: Hypertension in pregnancy: clinicalpathological correlations and remote prognosis. Medicine (Baltimore) 1981;60:267-276.

-72 Stepan H, Unversucht A, Wessel N, Faber R: Predictive value of maternal angiogenic factors in second trimester pregnancies with abnormal uterine perfusion. Hypertension 2007;49:818-824.

-73 Stepan H, Unversucht A, Wessel N, Faber R: Predictive value of maternal angiogenic factors in second trimester pregnancies with abnormal uterine perfusion. Hypertension 2007;49:818-824.

-74 Diab AE, El-Behery MM, Ebrahiem MA, Shehata AE: Angiogenic factors for the prediction of pre-eclampsia in women with abnormal midtrimester uterine artery Doppler velocimetry. Int J Gynaecol Obstet 2008;102:146-151.

-75 Chaiworapongsa T, Espinoza J, Gotsch F, et al: The maternal plasma soluble vascular endothelial growth factor receptor-1 concentration is elevated in SGA and the magnitude of the increase relates to Doppler abnormalities in the maternal and fetal circulation. J Matern Fetal Neonatal Med 2008;21:25-40.

76 Schoofs K, Grittner U, Engels T, et al: The importance of repeated measurements of the sFlt-1/PlGF ratio for the prediction of preeclampsia and intrauterine growth restriction. J Perinat Med -2014;42:61-68.

-77 Verlohren S, Galindo A, Schlembach D, et al: An automated method for the determination of the sFlt-1/PIGF ratio in the assessment of preeclampsia. Am J Obstet Gynecol 2010;202: 161.e1-e11.

-78 Ohkuchi A, Hirashima C, Suzuki H, et al: Evaluation of a new and automated electrochemiluminescence immunoassay for plasma sFlt-1 and PlGF levels in women with preeclampsia. Hypertens Res 2010;33:422-427.

79 Schiettecatte J, Russcher H, Anckaert E, et al: Multicenter evaluation of the first automated Elecsys sFlt-1 and PlGF assays in normal pregnancies and preeclampsia. Clin Biochem 2010;43:768-770
80 Verlohren S, Herraiz I, Lapaire O, et al: New gestational phase-specific cutoff values for the use of the soluble fms-like tyrosine kinase-1/ placental growth factor ratio as a diagnostic test for preeclampsia. Hypertension 2014;63: 346-352.

81 Rana S, Powe CE, Salahuddin S, et al: Angiogenic factors and the risk of adverse outcomes in women with suspected preeclampsia. Circulation 2012;125:911-919.

82 Rana S, Hacker MR, Modest AM, et al: Circulating angiogenic factors and risk of adverse maternal and perinatal outcomes in twin pregnancies with suspected preeclampsia. Hypertension 2012;60:451-458.

83 Rana S, Schnettler WT, Powe C, et al: Clinical characterization and outcomes of preeclampsia with normal angiogenic profile. Hypertens Pregnancy 2013;32:189-201.

84 Ness RB, Roberts JM: Heterogeneous causes constituting the single syndrome of preeclampsia: a hypothesis and its implications. Am J Obstet Gynecol 1996;175:1365-1370.

85 Verlohren S, Herraiz I, Lapaire O, et al: The sFlt-1/PlGF ratio in different types of hypertensive pregnancy disorders and its prognostic potential in preeclamptic patients. Am J Obstet Gynecol 2012;206:58.e1-e8.

86 Verlohren S, Melchiorre K, Khalil A, Thilaganathan B: Uterine artery Doppler, birth weight and timing of onset of pre-eclampsia: providing insights into the dual etiology of late-onset pre-eclampsia. Ultrasound Obstet Gynecol 2014;44:293-298.

-87 Klingel R, Gohlen B, Schwarting A, Himmelsbach F, Straube R: Differential indication of lipoprotein apheresis during pregnancy. Ther Apher Dial 2003;7:359-364.

88 Thadhani R, Kisner T, Hagmann H, et al: Pilot study of extracorporeal removal of soluble fms-like tyrosine kinase 1 in preeclampsia. Circulation 2011;124:940-950.
89 Miquerol L, Langille BL, Nagy A: Embryonic development is disrupted by modest increases in vascular endothelial growth factor gene expression. Development 2000;127:39413946.

90 Ferrara N, Carver-Moore K, Chen H, Dowd M, Lu L, O'Shea KS, Powell-Braxton L, Hillan KJ, Moore MW: Heterozygous embryonic lethality induced by targeted inactivation of the VEGF gene. Nature 1996;380:439-442.

91 Lee YM, Cope JJ, Ackermann GE, Goishi K, Armstrong EJ, Paw BH, Bischoff J: Vascular endothelial growth factor receptor signaling is required for cardiac valve formation in zebrafish. Dev Dyn 2006;235:29-37.

92 Armstrong EJ, Bischoff J: Heart valve development: endothelial cell signaling and differentiation. Circ Res 2004;95:459-470.

93 Llurba E, Sánchez O, Ferrer Q, Nicolaides KH, Ruíz A, Domínguez C, Sánchez-de-Toledo J, García-García B, Soro G, Arévalo S, Goya M, Suy A, Pérez-Hoyos S, Alijotas-Reig J, Carreras E, Cabero L: Maternal and foetal angiogenic imbalance in congenital heart defects. Eur Heart J 2014;35:701-707.

94 Llurba E, Syngelaki A, Sánchez O, Carreras E, Cabero L, Nicolaides KH: Maternal serum placental growth factor at 11-13 weeks' gestation and fetal cardiac defects. Ultrasound Obstet Gynecol 2013;42:169-174

95 Ikeda E, Achen MG, Breier G, Risau W: Hypoxia-induced transcriptional activation and increased mRNA stability of vascular endothelial growth factor in C6 glioma cells. J Biol Chem 1995;270:19761-19766.

-96 Levy AP, Levy NS, Goldberg MA: Post-transcriptional regulation of vascular endothelial growth factor by hypoxia. J Biol Chem 1996; 271:2746-2753.

97 Davis EF, Lazdam M, Lewandowski AJ, Worton SA, Kelly B, Kenworthy Y, Adwani S, Wilkinson AR, McCormick K, Sargent I, Redman C, Leeson P: Cardiovascular risk factors in children and young adults born to preeclamptic pregnancies: a systematic review. Pediatrics 2012;129:e1552-e1561. 